\title{
Fenologia, produção e produtividade de cinco genótipos de morangueiro nas condições edafoclimáticas do Município de Laranjeiras do Sul - PR
}

\author{
Phenology, production and productivity of five strawberry genotypes in edaphoclimatic conditions \\ in the Municipality of Laranjeiras do Sul - PR \\ Fenología, producción y productividad de cinco genotipos de fresa en condiciones edafoclimáticas \\ en el Municipio de Laranjeiras do Sul - PR
}

Recebido: 09/04/2021 | Revisado: 15/04/2021 |Aceito: 21/04/2021 | Publicado: 06/05/2021

\author{
Pricilia Moritz \\ ORCID: https://orcid.org/0000-0001-5200-4028 \\ Universidade Federal da Fronteira Sul, Brasil \\ E-mail: pricilamoritz@gmail.com \\ Cintia Izabela Vienc Hilatchuk \\ ORCID: https://orcid.org/0000-0002-0715-1907 \\ Universidade Federal da Fronteira Sul, Brasil \\ E-mail: cintia_vienchilatchuk@yahoo.com \\ Cláudia Simone Madruga Lima \\ ORCID: https://orcid.org/0000-0002-1953-1552 \\ Universidade Federal da Fronteira Sul, Brasil \\ E-mail: claudia.lima@uffs.edu.br \\ Gabriela Gerhardt da Rosa \\ ORCID: https://orcid.org/0000-0002-5023-3414 \\ CEDUP - Professor Jaldyr Bhering Faustino da Silva, Brasil \\ E-mail: birela89@gmail.com \\ Antonio Felippe Fagherazzi \\ ORCID: https://orcid.org/0000-0002-8731-2618 \\ Universidade do Estado de Santa Catarina, Brasil \\ E-mail: antonio.fagherazzi@gmail.com \\ Leo Rufato \\ ORCID: https://orcid.org/0000-0001-9545-7035 \\ Universidade do Estado de Santa Catarina, Brasil \\ E-mail: leoruffato@yahoo.com.br
}

\begin{abstract}
Resumo
O objetivo foi avaliar à fenologia, produção e produtividade de cinco genótipos de morangueiro. Para o experimento foi utilizado o sistema de produção orgânico, no solo sob cobertura de túneis baixos. Foram utilizadas quatro seleções italianas e uma cultivar norte americana. Avaliou-se floração, frutificação e colheita e duração dos diferentes estádios fenológicos, exigência térmica e aspectos produtivos dos genótipos. A seleção Italiana CREA FRF LAM01 apresentou maior produção por planta, porém todos os genótipos se mostraram aptos ao cultivo nas condições de Laranjeiras do Sul visto que se igualaram à realidade produtiva para a cultura na região.
\end{abstract}

Palavras-chave: Fragaria x ananassa; Seleções; Adaptabilidade; Exigência térmica.

\begin{abstract}
The objective was to evaluate the phenology, production and productivity of five strawberry genotypes. for the experiment, the organic production system was used, in the soil under cover of low tunnels. Four Italian selections and one North American cultivar were used. Flowering, fruiting and harvesting and duration of different phenological stages, thermal demand and productive aspects of genotypes were evaluated. The Italian selection CREA FRF LAM01 had the highest production per plant, but all genotypes proved to be suitable for cultivation under the conditions of Laranjeiras do Sul, since they matched the productive reality for the culture in the region.
\end{abstract}

Keywords: Fragaria x ananassa; Selections; Adaptability; Thermal requirement.

\section{Resumen}

El objetivo fue evaluar la fenología, producción y productividad de cinco genotipos de fresa. Para el experimento se utilizó el sistema de producción orgánica, en el suelo al amparo de túneles bajos. Se utilizaron cuatro selecciones italianas y una variedad norteamericana. Se evaluó la floración, fructificación y cosecha y duración de las diferentes etapas fenológicas, demanda térmica y aspectos productivos de genotipos. La selección italiana CREA FRF LAM01 tuvo la mayor producción por 
planta, pero todos los genotipos previstos para ser aptos para el cultivo en las condiciones de Laranjeiras do Sul, ya que coincidían con la realidad productiva del cultivo en la región.

Palabras clave: Fragaria x ananassa; Selecciones; Adaptabilidad; Requerimiento térmico.

\section{Introdução}

O morangueiro pertencente à família Rosaceae e gênero Fragaria, resultante do cruzamento entre as espécies $F$. chiloensis e $F$. virginiana é uma planta de interesse comercial em todo o mundo por apresentar frutas com coloração, sabor e aroma marcantes (Camargo, 2008, p.42). Outro fator importante é a rentabilidade da cultura (224\%) quando comparada à outros cultivos, justificando o crescente interesse de implantação (Morais et al., 2017)

A produção mundial anual de morango é acima de 8 milhões de toneladas por ano (United States Departament of Agriculture, 2018), sendo o Brasil o segundo maior produtor da América Latina com uma área de 4.300ha, a produção anual de morango no país é de aproximadamente 150 mil toneladas por ano, concentrada nos estados de São Paulo, Minas Gerais, Rio Grande do Sul e Paraná (Antunes, 2018, p.93), sendo as principais cultivares utilizadas a Camarosa de dias curtos e Albion de dias neutro (Fagherazzi et al., 2017, p.939).

No estado do Paraná, a cultura apresentou produção de 14,38 mil toneladas em uma área de 534 ha na safra de 2010, representando 7\% do valor bruto da produção frutícola do estado (SEAB, 2018). O município Laranjeiras do Sul pertencente ao território da Cantuquiriguaçu, está localizado na região sudoeste do estado do Paraná (IPARDES, 2018) e apresenta em seu território $82 \%$ de propriedades pertencentes à agricultura familiar (IBGE, 2006). Deste modo, a cultura do morangueiro se torna uma ótima opção, devido à rentabilidade que proporciona, por diversificar o sistema produtivo e consequentemente incrementar a renda, gerar emprego e fixar o homem no campo (Ronque et al., 2013, p.1034).

Para incentivar o plantio de determinada cultura em uma região são necessárias inúmeras pesquisas, entre elas, definição de genótipos e comportamento agronômico nas condições climáticas e edáficas locais, assim estudos de seleção e desempenho agrícola de genótipos de morangueiro na região são fundamentais. De acordo com Duarte Filho (2006, p.11), a seleção das cultivares é um dos pontos chave para o incentivo de implantação da cultura e para se alcançar o sucesso produtivo, pois é a interação genótipo-ambiente somada ao manejo, que determinara à produtividade e qualidade do fruto.

A cultura do morangueiro é altamente exigente em condições edafoclimáticas e técnicas de manejo para seu desenvolvimento, assim uma cultivar adaptada em determinada região quando introduzida à um novo local de cultivo que não apresente condições satisfatórias para se desenvolver expressará queda na produtividade e frutas com baixo valor comercial (Antunes et al., 2006, p.428)

O conhecimento fenológico de uma cultura é indispensável para o manejo bem como, para explicar fenômenos de ocorrência em resposta das plantas às condições climáticas e edáficas nas quais estão expostas (Pádua et al., 2015, p.72). As diferentes fases fenológicas ou fenofases permitem, por exemplo, a identificação do pico de floração, frutificação e colheita, bem como, a duração desses eventos o que é de extrema importância para o planejamento e tomada de decisão dos produtores.

Apesar de existirem estudos sobre a cultura do morangueiro no município de Laranjeiras do Sul/PR, não se conhece o comportamento de novos genótipos em sistema orgânico de produção na região. Assim o objetivo neste estudo foi avaliar a adaptabilidade de quatro seleções e uma cultivar de morangueiro no município de Laranjeiras do Sul - PR.

\section{Metodologia}

O experimento foi realizado na área experimental da Universidade Federal da Fronteira Sul, campus Laranjeiras do Sul-PR, localizada $25^{\circ} 24^{\prime} 28^{\prime \prime} \mathrm{S} 52^{\circ} 24^{\prime}, 58^{\prime} \mathrm{W}$ e altitude de $840 \mathrm{~m}$. O clima da região é classificado como (Cfb), clima temperado segundo a classificação de Köeppen-Geiger (1948), com temperatura média anual entre 18 e $19^{\circ} \mathrm{C}$ e precipitação de 1800 a 2000 mm.ano-1 (Caviglione et al., 2000). Durante o período de execução do experimento as médias de temperaturas 
mínimas e máximas ficaram entre 8,41 e $28,8^{\circ} \mathrm{C}$, respectivamente, e as de precipitação acumulada em aproximadamente 1.500,6mm (Figura 1) (UFFS, 2017).

Figura 1: Valores médios de precipitação $(\mathrm{mm})$, temperaturas $\left({ }^{\circ} \mathrm{C}\right)$ mínima, média e máxima do ar nos meses de avaliação de abril a dezembro de 2017, Laranjeiras do Sul-PR. Dados obtidos na estação climática da UFFS - Laranjeiras do Sul-PR.

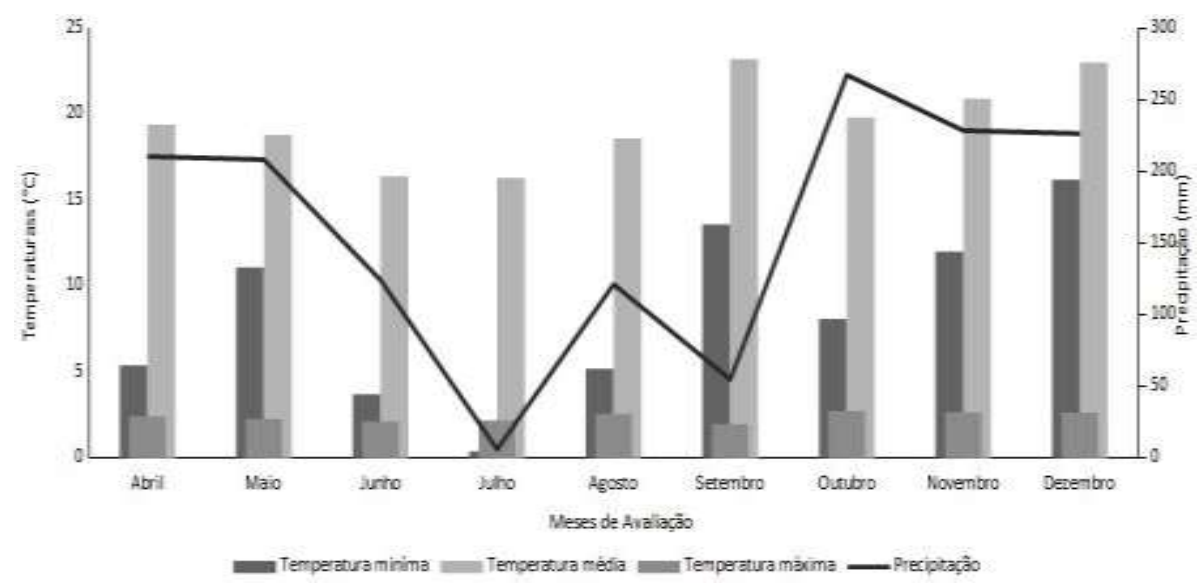

Fonte: Autores.

Como material vegetal foram utilizados cinco genótipo de morangueiro, sendo quatro seleções de origem italiana e uma cultivar norte americana sendo está registrada e tradicionalmente cultivada no Brasil. Os genótipos oriundos da Itália, foram provenientes do programa de melhoramento do Consiglio per la Ricerca in Agricoltura e l'Analisi dell'Economia Agraria - Unitá di Ricerca per la Frutticoltura di Forlì (CREA-FRF). Estes materiais foram enviados para o Brasil através de uma parceria com o Centro de Ciências Agroveterinárias (CAV) da Universidade do Estado de Santa Catarina (UDESC). Sendo identificados como CREA FRF LAM01, CREA FRF LAM18, CREA FRF PA109 de dias curtos e o CREA FRF FC104 de dias neutros, assim como, a cultivar Albion.

Os canteiros foram preparados manualmente apresentando dimensões de $15 \mathrm{~m}$ de comprimento, $1,2 \mathrm{~m}$ de largura e 0,30m de altura. A correção e adubação foi realizada de acordo com os resultados obtidos na análise de solo (Quadro 1), foi incorporado ao solo 2,250 kg de calcário em cada canteiro 30 dias antes do plantio e 2,660 Kg de esterco bovino curtido, 150g de Tetraborato de Sódio (Boráx) por canteiro. Para controle de fungos de solo e estimular o crescimento do sistema radicular foi aplicado o produto comercial SitimuControl na diluição $30 \mathrm{ml}$. L ${ }^{-1} /$ canteiro, fungicida biológico formulado a partir do fungo Trichoderma. Para adubação de manutenção foram realizadas aplicações semanais do fertilizante orgânico foliar Fish Férti "K" (5 ml. L $\left.{ }^{-1}\right)$, Eco-Fol-Cálcio (15 ml. 10 L. água $\left.{ }^{-1}\right)$ e Nutri-Kelp (10 ml. 10 L.água $\left.^{-1}\right)$. Para controle de doenças e insetos foram realizadas aplicações de extratos naturais semanalmente. O sistema de irrigação utilizado foi tubos gotejadores (4L.h-1 ${ }^{1}$ durante 40 minutos por dia).

Para a proteção de intempéries climáticas as mudas foram cobertas por filme plástico em polietileno de baixa densidade (PEBD) transparente, com 100\% de aditivação UV, com espessura de 100 micras na forma de túneis baixos, com altura de $0,75 \mathrm{~m}$ dos canteiros. Utilizou-se palhada de gramíneas como cobertura morta. 
Quadro 1: Composição química do solo na área destinada ao experimento no Setor de Olericultura da Área Experimental da UFFS.

\begin{tabular}{|l|l|l|l|l|l|l|l|l|l|l|l|l|}
\hline $\mathrm{pH}$ & $\mathrm{MO}$ & $\mathrm{P}$ & $\mathrm{K}$ & $\mathrm{Ca}$ & $\mathrm{Mg}$ & $\mathrm{A}$ & $\mathrm{H}^{+} / \mathrm{Al}$ & $\mathrm{CTC}$ & $\mathrm{Bases}$ & $\mathrm{Ca} / \mathrm{Mg}$ & $\mathrm{Ca} / \mathrm{K}$ & $\mathrm{Mg} / \mathrm{K}$ \\
$\mathrm{CaCl}_{2}$ & $\mathrm{~g} / \mathrm{dm}^{3}$ & Melich & & & & & & $\mathrm{pH}$ & $\mathrm{V} \%$ & & & \\
& & $\mathrm{Mg} / \mathrm{dm}^{3}$ & & & & & & 7,0 & & & & \\
\hline 5,63 & 39,17 & 175,60 & 0,664 & 4,72 & 1,61 & 0,00 & 4,51 & 11,48 & 60,7 & $2,9 / 1$ & $7,4 / 1$ & $2,5 / 1$ \\
\hline
\end{tabular}

Fonte: Autores.

Antes do plantio as mudas foram caracterizadas quanto à altura de plantas e comprimento de raízes, ambas verificadas com régua milimétrica expressa em cm; número de folhas e diâmetro da coroa, medido com o auxílio de paquímetro digital, expresso em milímetro. As plantas apresentaram valores médios de $12 \mathrm{~cm}$ de altura, $5 \mathrm{~cm}$ de comprimento de raiz, 3 trifólios e 6,5 mm de diâmetro de coroa. O transplantio ocorreu no dia sete do mês de abril de 2017, com espaçamento de $30 \mathrm{~cm}$ entre plantas e $40 \mathrm{~cm}$ entre linhas. Foi realizado banho de leite com chá de cavalinha nas mudas antes do plantio para proteção antifúngica.

As avaliações realizadas foram: datas de início de floração, frutificação e colheita e duração dos diferentes estádios fenológicos, exigência térmica e aspectos produtivos. Quanto aos parâmetros fenológicos foram baseados na metodologia de Antunes et al. (2006, p.428), os quais consideram início da floração quando 50\% das plantas apresentaram pelo menos uma flor aberta. A partir do início da floração determinou-se a data de início dos seguintes parâmetros: transplantio ao início da floração (T-F), início da floração ao início da colheita (IF-IC) e do transplantio ao início da colheita (T-IC). Para as avaliações de início de colheita consideraram-se maduras as frutas que apresentaram $75 \%$ de coloração vermelha na epiderme.

Para determinar a duração dos diferentes estádios fenológicos de floração, frutificação e maturação do morangueiro foi utilizada a seguinte classificação: estádio 1: aparecimento do botão floral, na base da roseta foliar, gemas floríferas com aspecto globoso e de coloração esverdeada; estádio 2: aparecimento das pétalas (estádio de balão); estádio 3: flores primárias, secundárias e terciárias completamente abertas; estádio 4: pétalas secas e caídas; estádio 5: formação da fruta com o receptáculo sobressalente da coroa das sépalas; estádio 6: aumento longitudinal da fruta promovida pela expansão celular; estádio 7: aumento do diâmetro da fruta com percepção dos aquênios no tecido do receptáculo; e estádio 8: início da maturação, maioria dos frutos brancos (Figura 2) (Antunes et al., 2006, p.428). 
Figura 2: Escala fenológica para os diferentes estádios identificados para a cultura.

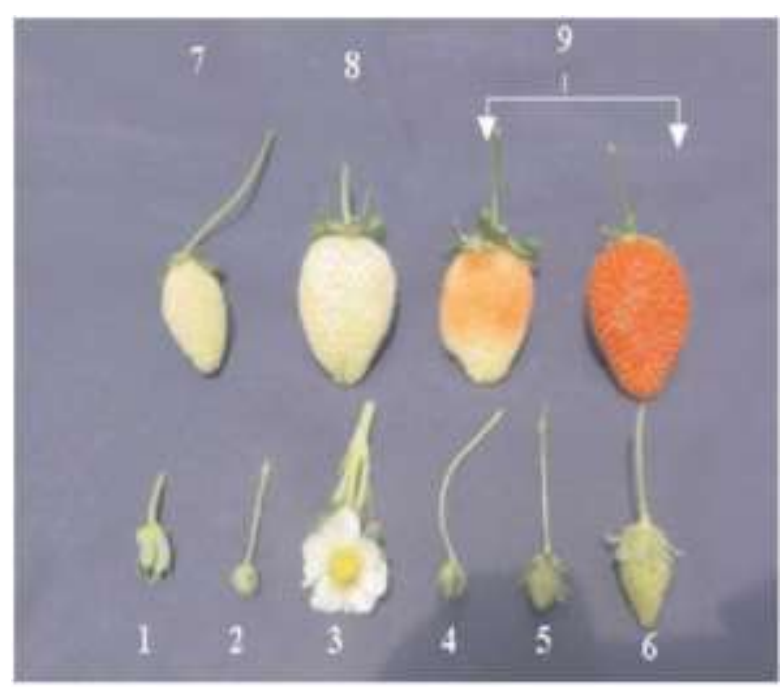

Fonte: Antunes et al, (2006, p.428).

As exigências térmicas foram determinadas pelo cálculo de graus- dia (GD), levando em consideração cada um dos subperíodos avaliados utilizando a temperatura base de $7^{\circ} \mathrm{C}$. O cálculo foi realizado de acordo com as seguintes equações propostas por Arnold, (1960): GD = $(\mathrm{Tm}-\mathrm{Tb})+(\mathrm{TM}-\mathrm{Tm}) / 2$, para Tm $>\mathrm{Tb}$; GD $=(\mathrm{TM}-\mathrm{Tb})^{2} / 2(\mathrm{TM}-\mathrm{Tm}), 120 \mathrm{para} \mathrm{Tm}<$ Tb e GD =0, para $\mathrm{Tb}>\mathrm{TM}$. Em que: $\mathrm{GD}=$ graus-dia; $\mathrm{TM}=$ temperatura máxima diária $\left({ }^{\circ} \mathrm{C}\right)$; Tm = temperatura mínima diária $\left({ }^{\circ} \mathrm{C}\right)$ e $\mathrm{Tb}=$ temperatura base $\left({ }^{\circ} \mathrm{C}\right)$.

Os dados climáticos utilizados foram fornecidos pela estação climatológica da Universidade Federal da Fronteira Sul (UFFS) campus Laranjeiras do Sul/PR. A soma térmica acumulada (STa, graus-dia) a partir do transplante foi calculada acumulando-se GD, ou seja, STa = $\sum$ (GD), proposta por Arnold (1960, p.683).

Os aspectos produtivos verificados foram: número de frutas por planta; massa fresca (g) verificada em balança digital, produção total (g) utilizando o somatório da massa de frutas obtidas ao longo dos meses de colheita e produtividade (t.ha ${ }^{-1}$ ). Foram contabilizados somente frutos acima de 6,0g, classificados como comerciais (Pereira et al., 2013, p.501).

O delineamento experimental utilizado foi inteiramente casualizado, com três repetições, sendo cada uma composta por 30 plantas totalizando 90 plantas por genótipo. Os resultados obtidos foram submetidos à análise de variância (ANOVA) e as médias dos tratamentos foram comparadas entre si pelo teste de Tukey a 5\% de significância utilizando o programa de estatística SISVAR (Ferreira, 1998, p.15).

\section{Resultados e Discussão}

A cultivar Albion e as seleções CREA FRF LAM18 e CREA FRF FC104 apresentaram menor número de dias para iniciar a floração $(80,63 ; 76,70$ e 84,20 dias, respectivamente), entretanto, do início da floração até a colheita (IF -IC) o menor período foi verificado com “Albion” que necessitou de 13 dias (Tabela 01). Do transplantio ao início da colheita (T-IC) a cultivar Albion e a seleção CREA FRF LAM18 apresentaram o menor ciclo fisiológico (94,40 e 105,03 dias, respectivamente) (Tabela 1). 
Tabela 1: Duração dos estádios fenológicos (dias), à partir da datas de transplantio ao início da floração (T-IF), início do florescimento ao início da colheita (IF-IC) e transplantio ao início da colheita (T-IC) de cinco genótipos (quatro seleções: CREA FRF LAM01, CREA FRF LAM18, CREA FRF FC 104 e CREA FRF PA109 e uma cultivar: Albion) de morangueiro para às condições edafoclimáticas de Laranjeiras do Sul-PR (UFFS, 2017)

\begin{tabular}{llll}
\hline $\begin{array}{l}\text { Genótipos } \\
\text { (Cultivar/Seleções) }\end{array}$ & $\begin{array}{l}\text { T-IF } \\
\text { (dias) }\end{array}$ & IF-IC & T-IC \\
\hline Albion & $80,63 \mathrm{~b}$ & $13,00 \mathrm{~d}$ & $94,40 \mathrm{c}$ \\
CREA FRF LAM01 & $103,66 \mathrm{a}$ & $31,23 \mathrm{a}$ & $134,90 \mathrm{a}$ \\
CREA FRF LAM18 & $76,70 \mathrm{~b}$ & $28,33 \mathrm{ab}$ & $105,03 \mathrm{c}$ \\
CREA FRF FC104 & $84,20 \mathrm{~b}$ & $29,66 \mathrm{a}$ & $113,86 \mathrm{bc}$ \\
CREA FRF PA109 & $104,90 \mathrm{a}$ & $22,60 \mathrm{c}$ & $127,90 \mathrm{ab}$ \\
\hline
\end{tabular}

*Data de transplante: 07/04/2017. Genótipos de dia neutro: Albion e CREA FRF FC104. Genótipos de dia curto: CREA FRF LAM01, CREA FRFLAM18 e CREA FRF PA109; Médias seguidas da mesma letra minúscula na coluna não diferem entre si pelo teste de Tukey à 5\% de significância. Fonte: Autores.

Tazzo et al. (2015, p.554), nas condições do Planalto Sul Catarinense observaram valores inferiores aos obtidos neste trabalho com 58 dias do transplantio ao início da floração para as cultivares Camino Real e Camarosa (ambas de dias curtos) e 51 dias para "San Andreas" e "Albion” (ambas de dias neutros), sendo a data de transplantio de 26 de junho de 2012.

Cocco et al. (2017), avaliando os mesmos genótipos utilizados neste experimento nas condições edafoclimáticas da Serra Gaúcha, com transplantio no dia 26 do mês de maio de 2016, obtiveram início da colheita em setembro, assim como verificado neste experimento para a seleção CREA FRF PA109.

Segundo Verdial, (2004, p.62) as cultivares de dias curtos florescem com temperaturas entre $8^{\circ} \mathrm{C}$ e $15^{\circ} \mathrm{C}$ e fotoperíodo inferior a 14 horas e as de dias neutros durante todo o ano, desde que as temperaturas se mantenham abaixo de $28^{\circ} \mathrm{C}$. As temperaturas médias superiores à $15^{\circ} \mathrm{C}$ registradas nos primeiros meses do período de avaliação provavelmente influenciaram no desenvolvimento das seleções de dias curtos retardando seu florescimento e corroborando para sua maior permanência na fase vegetativa.

A temperatura interna em túneis de cobertura plástica é superior ao ambiente externo, o que torna essencial o manejo diário dos mesmos, pois a renovação do ar depende do levantamento das cortinas laterais (Vasquez et al., 2005, p.139). Devido às altas taxas de precipitação nos meses iniciais ao experimento as cortinas não eram manejadas diariamente para evitar a incidência de doenças foliares, o que ocasionou uma restrição na renovação do ar interno e aumento das temperaturas o que pode ter colaborado para o retardo da diferenciação floral dos genótipos avaliados, o que provavelmente explica a diferença no período vegetativo encontrado neste trabalho em relação aos habituais descritos na literatura.

A seleção CREA FRF FC104 apresentou maior número de dias para o aparecimento do botão floral (I), com 8 dias, os demais genótipos foram precoces para este estádio com médias de 5 a 6 dias (Tabela 2). Para o estádio II, fenofase em que a gema florífera apresentava-se em estádio de balão e era verificado o aparecimento das pétalas, não houve diferença entre os genótipos que permaneceram de 3 a 5 dias neste estádio até que atingissem o estádio III, no qual a flor fica totalmente aberta e os estigmas prontos para receberem o grão de pólen de outra flor. No estádio III, as seleções tardias foram CREA FRF LAM01, CREA FRF PA109 de dias curtos (4,23 e 4,26 dias, respectivamente) e CREA FRF FC104 de dias neutros (4 dias), a qual não de diferenciou de “Albion” nem das demais seleções. Os genótipos permaneceram em média de 4 dias com a flor totalmente aberta até atingirem o estádio IV. 
Tabela 2: Duração (dias) de oito estádios fenológicos ${ }^{1}$ de cinco genótipos de morangueiro durante a floração, frutificação e maturação das frutas nas condições edafoclimáticas de Laranjeiras do Sul-PR (UFFS, 2017).

\begin{tabular}{|c|c|c|c|c|c|c|c|c|}
\hline \multirow{2}{*}{$\begin{array}{l}\text { Genótipos } \\
\text { (Cultivar/ } \\
\text { Seleções) }\end{array}$} & \multicolumn{8}{|c|}{ Estádios Fenológicos (dias) ${ }^{1}$} \\
\hline & I & II & III & IV & V & VI & VII & VIII \\
\hline Albion & $6,33 \mathrm{~b}$ & $3,44 \mathrm{a}$ & $3,22 \mathrm{~b}$ & $3,66 \mathrm{a}$ & $4,10 \mathrm{~b}$ & $5,33 \mathrm{a}$ & $4,77 \mathrm{a}$ & $9,21 \mathrm{a}$ \\
\hline $\begin{array}{l}\text { CREA FRF } \\
\text { LAM01 }\end{array}$ & $6,85 \mathrm{~b}$ & $5,00 \mathrm{a}$ & $4,23 \mathrm{a}$ & $4,12 \mathrm{a}$ & $3,88 \mathrm{~b}$ & $4,02 \mathrm{~b}$ & $5,56 \mathrm{a}$ & $7,26 \mathrm{~b}$ \\
\hline $\begin{array}{l}\text { CREA FRF } \\
\text { LAM18 }\end{array}$ & $6,13 \mathrm{~b}$ & $4,95 \mathrm{a}$ & $3,46 \mathrm{ab}$ & $3,23 \mathrm{a}$ & $4,03 \mathrm{~b}$ & $4,90 \mathrm{a}$ & $7,10 \mathrm{a}$ & $6,83 \mathrm{~b}$ \\
\hline $\begin{array}{l}\text { CREA FRF } \\
\text { FC104 }\end{array}$ & $8,00 \mathrm{a}$ & $3,33 \mathrm{a}$ & $4,00 \mathrm{ab}$ & $3,00 \mathrm{a}$ & $6,00 \mathrm{a}$ & $5,00 \mathrm{a}$ & $5,60 \mathrm{a}$ & $7,33 \mathrm{~b}$ \\
\hline $\begin{array}{l}\text { CREA FRF } \\
\text { PA109 }\end{array}$ & $5,36 \mathrm{~b}$ & $4,16 \mathrm{a}$ & $4,26 \mathrm{a}$ & $4,06 \mathrm{a}$ & $4,00 \mathrm{~b}$ & $3,76 \mathrm{~b}$ & $4,90 \mathrm{a}$ & $7,66 \mathrm{ab}$ \\
\hline
\end{tabular}

I= aparecimento do botão floral; II=aparecimento das pétalas (estádio de balão); III= flores completamente abertas; IV= pétalas secam e caem; V= formação do fruto; VI= aumento do tamanho do fruto; VII= fruto com percepção das sementes no receptáculo; e VIII= começo da maturação, maioria dos frutos brancos.* Data de transplantio: 07/04/2017. Genótipos de dia neutro: Albion e CREA FRF FC104. Genótipos de dia curto: CREA FRF LAM01, CREA FRFLAM18 e CREA FRF PA109; Médias seguidas da mesma letra minúscula na coluna não diferem entre si pelo teste de Tukey à $5 \%$ de significância. Fonte: Autores.

Para o estádio IV, fenofase em que as pétalas secam e caem, não houve diferença entre os genótipos que levaram em média 3,61 dias até alcançarem o próximo estádio (Tabela 02). Na fenofase $\mathrm{V}$, em que ocorre a formação de um pequeno fruto múltiplo, a seleção CREA FRF FC104 permaneceu maior número de dias neste estádio (6 dias) os demais genótipos aproximadamente 4 dias até que o estádio VI pudesse ser observado. Durante o estádio VI ocorre o aumento do tamanho do fruto e expansão celular, a cultivar Albion permaneceu neste estádio por 5,33 dias e à seleção CREA FRF PA109 apresentou a menor duração, 3,76 dias, até que pudesse ser observado o estádio VII.

Para o aumento do diâmetro do fruto e percepção dos aquênios (estádio VII) não houve diferença entre os genótipos, sendo a seleção CREA FRF LAM18 que permaneceu maior número de dias nessa fenofase (7,10 dias). O estádio VIII, em que os frutos se tornam totalmente brancos e atingem $75 \%$ da epiderme com coloração vermelha foi a fenofase em que se verificou os maiores valores, ou seja, maior período de permanência sendo que a cultivar Albion ficou neste estádio por 9,21 dias e a seleção CREA FRF LAM18 apresentou a menor duração para o período, de 6,83 dias (Tabela 02).

A duração dos estádios fenológicos encontrados neste trabalho foram superiores aos valores médios descritos por Antunes et al. (2006, p.428), trabalhando com as cultivares Oso Grande, Milsei-Tudla, Chandler e Dover (todas de fotoperíodo curto), cultivadas em estufa galvanizada em Pelotas-RS, para as quais o estádio de maior duração foi o IV (as pétalas secam e caem), com variação de 8,4 à 17 dias, fenômeno este que os autores denominam de "pétalas persistentes", o que não foi observado para os genótipos avaliados neste trabalho tendo em vista que o estádio IV teve duração média de 4 dias.

A temperatura e o fotoperiodismo são os fatores ambientais que mais influenciam no desenvolvimento do morangueiro, sendo a temperatura o mais importante, pois quando elevada a diferenciação floral cessa e o crescimento vegetativo é induzido e em condições inferiores à temperatura base para a cultura $\left(7^{\circ} \mathrm{C}\right)$ a floração também é inibida, porém com o acúmulo de horas de frio as plantas começam a concentrar substâncias de reserva, o que as prepara para a diferenciação floral e frutificação (Ronque, 1998).

Quanto à necessidade de acúmulo de temperatura para todos os períodos (T-IF, IF-IC e T-IC) a seleção CREA FRF LAM01 apresentou as maiores exigências térmicas e a cultivar Albion as menores $(870,45 ; 308,71 ; 1.179,00$ e 618,71; 134,66; 753,38 graus-dias, respectivamente) (Tabela 03). Esses resultados de graus-dias verificados para genótipo Albion são coerentes 
com o número de dias para completar os respectivos períodos, em que se observou as menores médias em relação aos demais genótipos, ou seja, sendo precoce em relação aos demais (Tabela 3).

Tabela 3: Graus-dias acumulados de cinco genótipos de morangueiro para os períodos de transplantio ao início do florescimento (T-IF); início de florescimento ao início da colheita (IF-IC), transplantio ao início da colheita (T-IC) de quatro seleções (CREA FRF LAM01, CREA FRF LAM18, CREA FRF FC 104 e CREA FRF PA109) e uma cultivar (Albion) de morangueiro para às condições edafoclimáticas de Laranjeiras do Sul-PR (UFFS,2017)

\begin{tabular}{llll}
\hline $\begin{array}{l}\text { Genótipos } \\
\text { (Cultivar/Seleções) }\end{array}$ & $\begin{array}{l}\text { T-IF } \\
\text { (Graus Dias) }\end{array}$ & IF-IC & T-IC \\
\hline Albion & $618,71 \mathrm{~b}$ & $134,66 \mathrm{c}$ & $753,38 \mathrm{c}$ \\
CREA FRF LAM01 & $870,45 \mathrm{a}$ & $308,71 \mathrm{a}$ & $1.179,00 \mathrm{a}$ \\
CREA FRF LAM18 & $581,33 \mathrm{c}$ & $276,51 \mathrm{~b}$ & $856,18 \mathrm{bc}$ \\
CREA FRF FC104 & $653,51 \mathrm{~b}$ & $297,66 \mathrm{ab}$ & $951,18 \mathrm{abc}$ \\
CREA FRF PA109 & $857,13 \mathrm{a}$ & $249,90 \mathrm{~b}$ & $1.107,03 \mathrm{a}$ \\
\hline
\end{tabular}

*Data de transplante: 07/04/2017. Genótipos de dia neutro: Albion e CREA FRF FC104. Genótipos de dia curto: CREA FRF LAM01, CREA FRFLAM18 e CREA FRF PA109; Médias seguidas da mesma letra minúscula na coluna não diferem entre si pelo teste de Tukey à $5 \%$ de significância. Fonte: Autores.

Tazzo et al. (2015, p.554), avaliando as cultivares Albion de dia neutro e Camarosa de dia curto no planalto Catarinense no ano de 2012, registraram valores inferiores para o período do transplantio ao início da floração em relação aos obtidos para os genótipos avaliados neste trabalho (307,25 e 376,86 graus-dias, respectivamente). Já para os períodos do transplantio ao início da colheita os autores registraram valores superiores aos verificados nesta pesquisa, tanto para genótipos de dias neutros (Albion: 599 graus-dias) quanto para as seleções de dias curtos (Camarosa: 1.137,75 graus-dias), com exceção da seleção CREA FRF LAM01 que neste experimento apresentou a maior exigência térmica para o acúmulo de temperaturas para o período entre o transplantio e início da colheita (1.179,00 graus-dias).

A combinação genética das plantas apresentam necessidades diferentes de temperatura e fotoperíodo para seu desenvolvimento (Mendonça et al. 2012, p.297) o que pode explicar o comportamento dos genótipos avaliados neste trabalho. As temperaturas abaixo da base para a cultura $\left(7^{\circ} \mathrm{C}\right)$, registradas no mês de julho, combinadas com às condições de manejo podem ter influenciado no desenvolvimento das plantas necessitando assim de uma maior exigência térmica para concluir seus ciclos fenológicos.

No decorrer das 22 semanas de avaliação de colheita o maior de número de frutas, produção e produtividade foram verificados para genótipo CREA FRF LAM01 (26,1 frutos. planta ${ }^{-1}$; 399,24 g.planta ${ }^{-1}$ e 29,4 t.ha ${ }^{-1}$ respectivamente). Os menores valores para estas variáveis foram registrados pelas seleções de dias curto CREA FRF LAM18 e CREA FRF PA109 $\left(19,80 ; 314,47 \mathrm{~g} ; 23,58\right.$ t.ha $^{-1}$ e 20,$40 ; 314,47 \mathrm{~g} ; 23,58$ t.ha $\left.^{-1}\right)$. Para massa fresca das frutas não houve diferença entre os genótipos, que foi de aproximadamente $15 \mathrm{~g} \cdot$ fruta $^{-1}$ (Tabela 4). 
Tabela 4: Número total de frutas, massa fresca $\left(\mathrm{g}_{\text {gruta }}{ }^{-1}\right)$ das frutas, produção (g.planta $\left.{ }^{-1}\right)$ e produtividade (t.ha $\left.{ }^{-1}\right)$, cinco genótipos (quatro seleções: CREA FRF LAM01, CREA FRF LAM18, CREA FRF FC 104 e CREA FRF PA109 e uma cultivar: Albion) de morangueiro para às condições edafoclimáticas de Laranjeiras do Sul-PR (UFFS, 2017).

\begin{tabular}{|c|c|c|c|c|c|}
\hline $\begin{array}{l}\text { Genótipos } \\
\text { Cultivar/ } \\
\text { Seleção }\end{array}$ & & $\begin{array}{l}\text { Número Total de } \\
\text { frutas }\end{array}$ & $\begin{array}{l}\text { Massa fresca } \\
\left(\text { g.fruta }{ }^{-1}\right)\end{array}$ & $\begin{array}{l}\text { Produção } \\
\left.\text { (g.planta }^{-1}\right)\end{array}$ & $\begin{array}{l}\text { Produtividade } \\
\left(\text { t.ha }{ }^{-1}\right)\end{array}$ \\
\hline Albion & & $24,50 \mathrm{~b}$ & $14,33 \mathrm{a}$ & $347,24 b$ & $26,04 \mathrm{~b}$ \\
\hline $\begin{array}{l}\text { CREA } \\
\text { LAM01 }\end{array}$ & FRF & $26,10 \mathrm{a}$ & $15,41 \mathrm{a}$ & $399,24 \mathrm{a}$ & $29,94 \mathrm{a}$ \\
\hline $\begin{array}{l}\text { CREA } \\
\text { LAM18 }\end{array}$ & FRF & $19,80 \mathrm{c}$ & $15,95 \mathrm{a}$ & $314,47 \mathrm{bc}$ & $23,58 \mathrm{c}$ \\
\hline $\begin{array}{l}\text { CREA } \\
\text { FC104 }\end{array}$ & FRF & $24,50 \mathrm{~b}$ & $14,30 \mathrm{a}$ & $347,24 \mathrm{~b}$ & $26,04 \mathrm{~b}$ \\
\hline $\begin{array}{l}\text { CREA } \\
\text { PA109 }\end{array}$ & FRF & $20,40 \mathrm{c}$ & $15,95 \mathrm{a}$ & $314,70 \mathrm{bc}$ & $23,58 \mathrm{c}$ \\
\hline
\end{tabular}

*Data de transplante: 07/04/2017. Genótipos de dia neutro: Albion e CREA FRF FC104. Genótipos de dia curto: CREA FRF LAM01, CREA FRFLAM18 e CREA FRF PA109; Médias seguidas da mesma letra minúscula na coluna não diferem entre si pelo teste de Tukey à $5 \%$ de significância. Fonte: Autores.

Os valores para massa fresca das frutas e produção observados neste trabalho são inferiores aos verificados por Cocco et al. (2017), que avaliaram os mesmos genótipos em Farroupilha -RS no ano de 2016, registrando produção de 408,0 g.planta${ }^{1}$ e 23,4 g.fruta ${ }^{-1}$ para a cultivar Albion e 613,5 g.planta ${ }^{-1}$ e 25,2 g.fruta ${ }^{-1}$ para a seleção CREA FRF PA109.

As médias obtidas para massa fresca das frutas são próximas aos valores verificados por Trevisan et al., (2017, p.107) nas condições edafoclimáticas de Laranjeiras do Sul utilizando a cultivar Milsei Tudla de dias curto, em que obtiveram frutas com massa entre 10 a 16 gramas, valores estes semelhantes ao encontrados para os genótipos de mesmo comportamento ao fotoperíodo avaliados neste trabalho. Quando comparado cultivares de dias neutro, Franco et al. (2017, p.118), nas condições de Laranjeiras do Sul com a cultivar San Andreas obtiveram frutas com massa entre 10 e 19 gramas próximos ao encontrados para "Albion" neste trabalho.

Os resultados de produtividade verificados neste trabalho corroboram com os descritos por Camargo (2010, p.283), em sistema orgânico de produção em Guarapuava-PR, obtendo valores de 25,86 t.ha ${ }^{-1}$ para a cultivar Campinas, 25,44 t.ha ${ }^{-1}$ para "Dover" e 25,15 t.ha ${ }^{-1}$ para a cultivar Ventana acentuando o desempenho dos genótipos avaliados neste trabalho com a realidade da região.

A radiação solar é um fator importante para a diferenciação floral e desenvolvimento das frutas no morangueiro (XU et al., 2014, p.184) pois quando elevada torna o metabolismo de fotoassimilados eficiente (Martínez-Ferri, 2015, p.75). A área experimental em que esta pesquisa foi desenvolvida está localizada às margens de uma plantação de Eucalyptus spp. o que proporcionou sombreamento sobre as plantas, o que pode ter causado menor incidência luminosa, atreladas a combinação genética das plantas, diminuindo assim a taxa fotossintética e consequentemente influenciando no desempenho produtivo. Contudo, os genótipos atenderam os valores para estimativa de produtividade esperado dentro da realidade da região mostrando-se aptos para o cultivo nas condições edafoclimáticas de Laranjeiras do Sul.

Durante o período de avaliação foram registradas temperaturas máximas com média de $28^{\circ} \mathrm{C}$ o que pode ter ocasionado inibição da diferenciação floral. Brazanti (1989) descreveu temperaturas acima de $25^{\circ} \mathrm{C}$ como causadoras da inibição floral para a cultura e temperaturas acima de $32^{\circ} \mathrm{C}$ como responsáveis pelo abortamento das flores. Às temperaturas inferiores à temperatura base verificadas nesta pesquisa para a cultura cessaram a diferenciação floral dos genótipos, principalmente dos de dias neutro, já que mesmo insensíveis ao fotoperiodismo respondem de forma negativa a temperaturas amenas. 
A primavera se inicia no mês de setembro, período até o qual os dias apresentam até 12 horas de luz e posteriormente começam a ficar mais longos e com temperaturas elevadas, o comportamento da seleção CREA FRF LAM01 foi tardio quando comparado às outras seleções de dias curto, pois durante os primeiros meses de avaliação apresentou maior crescimento vegetativo e consequente acumulo de substâncias de reserva, quando os dias se tornaram longos entrou no período de frutificação se comportando de forma semelhante a cultivares de dias longo.

\section{Considerações Finais}

Os genótipos CREA FRF LAM01 e CREA FRF PA109 apresentaram maior ciclo fenológico. Entretanto a maior exigência térmica foi observada para CREA FRF LAM01 e CREA FRF FC104.

A seleção CREA FRF PA109 se mostrou mais precoce para os estádios fenológicos, enquanto o maior número de frutos, produção e produtividade foram registrados para CREA FRF LAM01. Deste modo, as estimativas de produtividades encontradas para todos os genótipos estão dentro do encontrado para a realidade da cultura na região, o que os torna adaptadas as condições edafoclimáticas de Laranjeiras do Sul - PR.

\section{Agradecimento}

Os autores deste trabalho agradecem o apoio PES: 2020-0308 Edital No 270/GR/UFFS/2020 (RETIFICADO) e de Resultado Final do Edital No 381/GR/UFFS/2020.

\section{Referências}

Antunes ,O.T., Calvete E.O., Rocha, H.C., Nienow, A.A., Mariani,F., Wesp, C.L. 2006. Floração, frutificação e maturação de frutos de morangueiro cultivados em ambiente protegido. Horticultura Brasileira. 24, p. 426-430.

Antunes, L.E.C. 2018. Brasil é o maior produtor de morango da América do Sul. Campo \& Negócio-HF. Uberlândia-MG, 7, p. 92-94.

Arnold, C. Y. Maximum-Minimum temperature as a basis for computing heat units. 1960. Horticultural Science, San Francisco, 76, p. 682-692,

Brazanti, E.C.1989. La fresa. Madri: Mundi-prensa. 386p.

Caviglione, J. H., Kiihl, L. R. B., Caramori, P. H., Oliveira, D. de. Cartas Climáticas do Paraná. Londrina- PR: IAPAR, CD, 2000.

Camargo, L. K. P. Produtividade e qualidade de cultivares de morangueiro em sistemas orgânico e convencional na Região de Guarapuava - PR. 98f. Dissertação (Mestrado) - Universidade Estadual do Centro Oeste, Guarapuava. 2008.

Camargo, L. K. P., Resende, J.T.V., Galvão, A.G., Camargo, C.K., Baier, J.E., 2010. Desempenho produtivo e massa média de frutos de morangueiro obtidos de diferentes sistemas de cultivo. Revista Ambiência Guarapuava, Guarapuava, 6, p. 281-288.

Cocco, C., Andrade, W. A., Giacomel, F., Fagherazzi, A. F., Ruffato, L. Desempenho de genótipos italianos de morangueiro na Serra Gaúcha. In. IX Seminário Brasileiro sobre Pequenas Frutas. Vacaria. RS. 2017.

Duarte Filho, J. 2006 Cultivares de morango. In: Carvalho, S. P. (Coord.). Boletim do morango: cultivo convencional, segurança alimentar, cultivo orgânico. Belo Horizonte: FAEMG. p. 9-14.

Fagherazzi, A.F., Grimaldi, F., Kretzschmar, A.A., Molina, A.R., Gonçalves, M.A., Antunes, L.E.C., Baruzzi, G. Rufato, L. 2017. Strawberry production progress in Brazil. Acta Horticultura. 1156, p.937-940.

Ferreira, D. F. Sisvar - sistema de análise de variância para dados balanceados. Lavras: UFLA, 1998. 19 p.

Franco, E. O; Uliana, C; Lima, C. S. M. 2017. Características físicas e químicas de morango "San Andreas" submetido a diferente posicionamento de slab, densidade de plantio e meses de avaliação. Revista Ibero Americana de Tecnologia Pos-colheita. 18, p. 115-120.

IBGE. Censo Agropecuário de 2006. Disponível em:< http://www.sidra.ibge.gov.br> Acesso em 19 de maio de 2018.

IPARDES. Caderno Estatístico - Município de Laranjeiras do Sul. 2018.

Martínez-Ferri, E.; Soria, C., Ariza, M.T., Medina, J.J., Dominguez, P., Muriel, J.L. 2015. Water relations, growth and physiological response of seven strawberry cultivars (Fragaria x ananassa Duch) to different water availability. Agricultural Water Management, 164, p. 73-82. 
Research, Society and Development, v. 10, n. 5, e25310514864, 2021

(CC BY 4.0) | ISSN 2525-3409 | DOI: http://dx.doi.org/10.33448/rsd-v10i5.14864

Mendonça, H., Müller, A.L., Tazzo, I.F., Cavlete, E.O. 2012. Accumulated leaf number in strawberry cultivars grown in a greenhouse. Acta Horticulturae, The Hague, 926 , p. $295-300$.

Morais, M.A, Franco, A. C. D. O. Produção de morangos em regiões não tradicionais. Seminário de Iniciação Científica IFMG. 2017.

Oliveira, A.C.B., Bonow, S. 2012. Novos desafios para o melhoramento genético da cultura do morangueiro no Brasil. Informe Agropecuário, Belo Horizonte, v. 33, p. 21-26.

Pádua, J. G. de, Rocha, L. C. D., Gonçalves, E. D., Araújo, T. H. de, Carmo, E. L. do, Costa, R. 2015. Comportamento de cultivares de morangueiro em Maria da Fé e Inconfidentes, sul de Minas Gerais. Revista Agrogeoambiental, 7, p. 69-79.

PARANÁ (Estado). Secretaria de Estado da Agricultura e Abastecimento. Morango - Área e Produção por região administrativa da SEAB - 2007 a 2011.

Pereira, W.R., Souza, R. J., Yuri, J.E., Ferreira, S. 2013. Produtividade de cultivares de morangueiro submetidas à diferentes épocas de plantio. Horticultura Brasileira, 31, p. 500-503.

Ronque, E.R.V. Cultura do morangueiro: revisão prática. Curitiba: EMATER-PR. p. 206, 1998.

Ronque, E.R.V., Ventura, M.U., Júnior, D.S., Macedo, R.B., Campos, B.R.S. 2013. Viabilidade da Cultura do Morangueiro no Paraná-Brasil. Revista Brasileira de Fruticultura. Jaboticabal - SP, 35 p. 1032-1041.

Tazzo, I. F., Fagherazzi, A. F., Lerin, S., Kretzschmar, A. A., Rufato, L. 2015. Exigência térmica de duas seleções e quatro cultivares de morango cultivado no planalto catarinense. Revista Brasileira de Fruticultura. Jaboticabal - SP. 37, p.550-558.

Trevisan, F, Lima, C. S. M, Pinto, V. Z, Bonome, L. T. S, Liz, K. M. 2017. Ácido salicílico no desenvolvimento de plantas e nas características físicoquímicas de frutas de morango "Milsei Tudla". Revista. Ibero Americana de Tecnologia Pos-colheita. 18, p. 106-114.

UNITED STATES DEPARTMENT OF AGRICULTURE. Production, supply and distribution online.

Vasquez, M. A. N., Folegatti, M. V., Dias, N. S., Silva, C. R. 2005. Efeito do ambiente protegido cultivado com melão sobre os elementos meteorológicos e sua relação com as condições externas. Engenharia Agrícola, 25, p. 137-143.

Verdial, M. F. Frigoconservação e vernalização de mudas de morangueiro (Fragaria x ananassa Duch.) produzidas em sistemas de vasos suspensos. $71 \mathrm{f}$. Tese (Doutorado em Agronomia) - Escola Superior de Agricultura Luiz de Queiroz, Universidade de São Paulo, Piracicaba, 2004.

Xu, F., Shi, L., Chen, W., Cao, S., Su, X., Yang, Z. 2014. Effect of blue light treatment on fruit quality, antioxidant enzymes and radical-scavenging activity in strawberry fruit. Scientia Horticulturae, 175, p.181- 186. 